\title{
Near-Net-Shape Fabrication of Porous Alumina-Spinel Castings
}

\author{
Minoru Hashiba*, Akinobu Harada, Naoki Adachi, Seizo Obata, \\ Osamu Sakurada and Koichi Hiramatsu
}

Gifu University, Gifu 501-1193, Japan

\begin{abstract}
The dispersion and fluidity of aqueous platelet $\gamma$-alumina slurries were enhanced by addition of ammonium polyacrylate (PAA) as a dispersant at $\mathrm{pH}$ 10. Magnesia powder was mixed with the slurries using a planetary mixer for $150 \mathrm{~s}$ after ball milling of the slurries for $24 \mathrm{~h}$. Magnesia was eluted gradually into the aqueous media by formation of a chelate with PAA. The slurries were solidified by PAA deficiency because of reduction of the electrostatic repulsive force between the alumina particles. The degree of shrinkage of the green body on drying was very small, and this was therefore regarded as a near-net-shaping process. A porosity of about $60 \%$ and strength of $45 \mathrm{MPa}$ were obtained in bodies fired at $1300^{\circ} \mathrm{C}$ and the mean pore diameter was $0.6 \mu \mathrm{m}$.
\end{abstract}

(Received June 21, 2005; Accepted September 28, 2005; Published December 15, 2005)

Keywords: porous body, $\gamma$-alumina, magnesia, spinel, direct casting

\section{Introduction}

Among the porous ceramics, alumina $\left(\mathrm{Al}_{2} \mathrm{O}_{3}\right)$ porous ceramics have been widely used as filters, fuel-cell electrodes, and membrane reactors because of their chemical and thermal stability. The properties of high porosity, monomodal pore diameter, and good strength characteristics are preferred for these uses. In addition, to the residual processes, the shaping process is very important to obtain desirable properties. Shaping through aqueous media is especially important in terms of environmental impact, safety, and cost. More recent direct casting methods, ${ }^{1)}$ such as gel casting ${ }^{2,3)}$ and direct coagulation casting, ${ }^{4-7)}$ are based on a colloidal process ${ }^{8)}$ controlled by the optimum conditions of processing factors: i) types of media and dispersant; ii) ceramic powder loading; and iii) the amount and molecular weight of the dispersant. Previously, we reported that the dispersion and fluidity of aqueous $\mathrm{Al}_{2} \mathrm{O}_{3}$ slurries were enhanced by addition of zirconium acetate ${ }^{9)}$ or ammonium polyacrylate (PAA) ${ }^{10,11)}$ and that there are optimum amounts and molecular weights of PAA for use in this process. Under optimum conditions, the green compact with theoretical density (T.D.) above 60 mass $\%$ could be obtained through the slip casting process using a plaster of Paris mold. However, the slip casting process has a number of problems, such as restriction of the number of molds that can be utilized and contamination of the compact from the mold. On the other hand, direct casting is superior to slip casting as shaping can be performed without any restriction of the mold. We reported that the $\mathrm{Al}_{2} \mathrm{O}_{3}$ slurry was solidified by increasing the ionic strength with the addition of aluminum nitride or yttrium oxide because this markedly reduces the electrostatic repulsive force between the $\mathrm{Al}_{2} \mathrm{O}_{3}$ particles. ${ }^{12,13)}$ Aluminum nitride and/or yttrium oxide form various aluminum and/or yttrium species by hydrolysis with changing $\mathrm{pH}$ : i.e., ions, oxide ions, hydroxide, and ammonium ions in aluminum nitride. We noted that magnesia $(\mathrm{MgO})$ also retained the action of solidification because this was gradually eluted into aqueous media in the alkaline region and we expected that $\mathrm{MgO}$ will be available for strengthening of the three-

*Corresponding author, E-mail: hashiba@apchem.gifu-u.ac.jp dimensional framework of the porous body because $\mathrm{MgO}$ forms $\mathrm{MgAl}_{2} \mathrm{O}_{4}$ (spinel) to react with $\mathrm{Al}_{2} \mathrm{O}_{3}$ at high temperatures above $1,000^{\circ} \mathrm{C}$. For fabrication of the porous body, the present study was performed to elucidate the effects of $\mathrm{MgO}$ on the shaping of aqueous high solid-loaded platelet $\gamma-\mathrm{Al}_{2} \mathrm{O}_{3}$ slurries dispersed and thickened using PAA. We measured the following processing factors: i) the elution rate of $\mathrm{MgO}$ into aqueous media; ii) the onset time of solidification of the slurry with differences in the amount of $\mathrm{MgO}$ added; iii) the density and shrinkage of green and sintered compacts; and iv) porosity and mean pore diameter of compacts.

\section{Experimental Procedures}

\subsection{Materials}

Platelet- $\mathrm{Al}_{2} \mathrm{O}_{3}$ used in the present study was $\gamma-\mathrm{Al}_{2} \mathrm{O}_{3}$ (BMM-B, Kawai Lime Co., Ogaki, Japan) with an average particle size of $1 \mu \mathrm{m}$ and aspect ratio of 10 . MgO powder (GR, Nacalai Tesque, Kyoto, Japan) was used to control solidification. PAA (average molecular weight, 6,200) was prepared by neutralization of polyacrylic acid (Aldrich Chemical Co., Milwaukee, WI, USA) with ammonium hydroxide.

\subsection{Shaping process}

$\mathrm{Al}_{2} \mathrm{O}_{3}$ slurries were prepared as follows: $\mathrm{Al}_{2} \mathrm{O}_{3}$ powder was added to water containing various amounts of PAA, calculated on a dry weight basis (dwb) relative to the $\mathrm{Al}_{2} \mathrm{O}_{3}$ powder. The water used to prepare all of the slurries was distilled and purified using a Milli-Q system (Milli-Q Plus, Millipore Co., Bedford, MA, USA). MgO powder was mixed with the slurries at a mole fraction of 1:4 relative to $\mathrm{Al}_{2} \mathrm{O}_{3}$ powder using a planetary mixer (MS-SNB-350N, Matsuo Ind., Osaka, Japan) for $150 \mathrm{~s}$ after ball milling of the slurries for $24 \mathrm{~h}$. Then, the slurries were cast into plastic molds and left to stand in a climatic chamber with controlled humidity $(97 \%)$ and temperature $\left(27^{\circ} \mathrm{C}\right)$ for $24 \mathrm{~h}$. Solidified bodies were air-dried at room temperature for $24 \mathrm{~h}$. Green bodies obtained in this experiment measured $80 \times 50 \times 6 \mathrm{~mm}$. Sintered bodies were obtained by firing the green bodies at $1,100-1,400^{\circ} \mathrm{C}$ for $2 \mathrm{~h}$. 


\subsection{Measurements}

To determine the amount of $\mathrm{MgO}$ eluted, $1 \mathrm{~g}$ of $\mathrm{MgO}$ was added to $50 \mathrm{~mL}$ of aqueous solution with and without PAA at pH 7 and 10 and left to stand for various durations. Magnesium in the supernatant was determined using an ICP-AES (PS1000UV, Leeman Labs, Hudson, NH, USA). The onset time of solidification of the slurry was determined by measurement of the storage modulus $\left(G^{\prime}\right)$ at $25^{\circ} \mathrm{C}$ using a controlled stress rheometer (RS-150, Haake, Karlsruhe, Germany) with a double gap cylinder (DG-41). The crystalline phase was identified by XRD (MXP3, Bruker AXS, Yokohama, Japan). Microstructural observations were conducted by scanning electron microscopy (S-4300, Hitachi, Tokyo, Japan). Porosity of the sintered porous body was measured by water intrusion in a vacuum chamber. Pore distribution and mean pore diameter were measured using a mercury porosimeter (Pore Master 60, Quantachrome, Boynton Beach, FL, USA). The bending strength data were obtained by a three-point bending test (Tensilon UCT-5T, Orientec, Saitama, Japan). The densities of the green compacts were calculated from their size and weight. The fired densities were measured by the Archimedes method.

\section{Results and Discussion}

\subsection{Effects of PAA on fluidity of the $\mathrm{Al}_{2} \mathrm{O}_{3}$ slurry}

A thickened fluid slurry was preferable for the direct casting method. Figure 1 shows the shear stress-shear rate curves (flow curves) of the slurries in the presence of various amounts of PAA. A viscosity jump was observed in the flow curve of the slurry with 0.75 mass $\%$ of PAA because of the abrupt formation of a "house of cards" structure from platelike $\mathrm{Al}_{2} \mathrm{O}_{3}$ particles. On the other hand, the addition of an excess of PAA (1.25 mass\%) markedly reduced the fluidity of the slurry. This result indicated that addition of 0.9 mass $\%$ of PAA was preferable for enhancing the fluidity of the slurries.

\subsection{Elution of MgO into aqueous media}

The elution behavior of $\mathrm{MgO}$ into aqueous media is the most important parameter in the direct casting method. Figure 2 shows the time dependence of the amount of $\mathrm{MgO}$

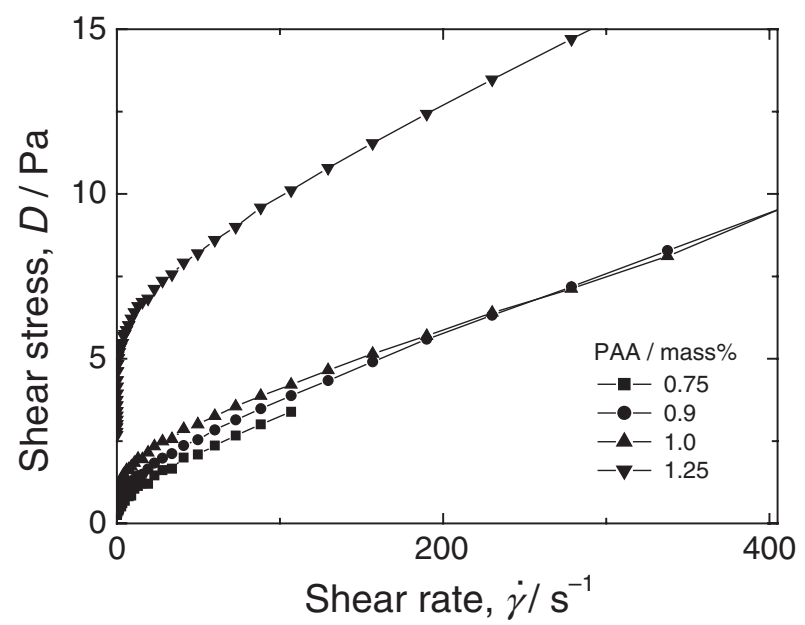

Fig. 1 Fluidity of the 60 mass $\% \mathrm{Al}_{2} \mathrm{O}_{3}$ slurries in the presence of various amounts of PAA.

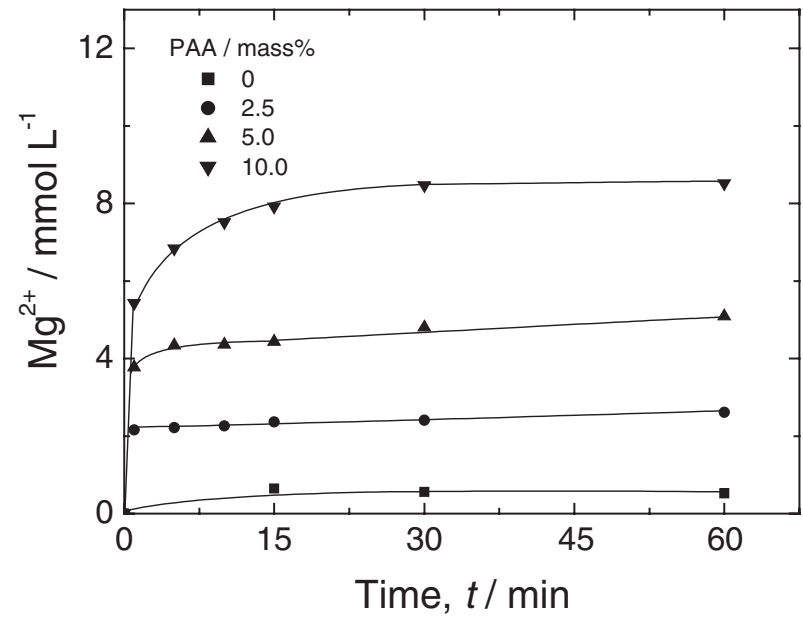

Fig. 2 Elution of $\mathrm{MgO}$ into the aqueous media with various concentrations of PAA.

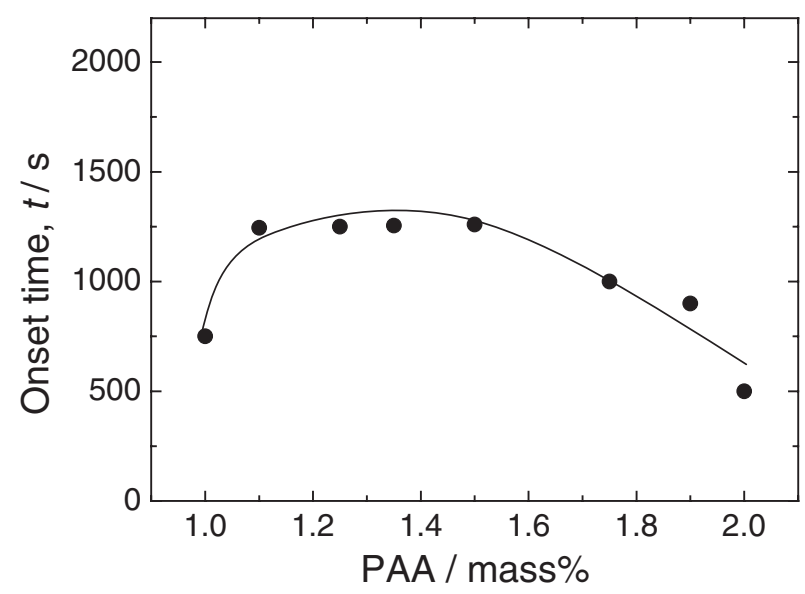

Fig. 3 The solidification onset time of the slurries with various concentrations of PAA.

eluted into the aqueous media with various concentrations of PAA at $\mathrm{pH} \mathrm{10.} \mathrm{The} \mathrm{amount} \mathrm{of} \mathrm{Mg}$ in the media increased gradually with elution time and with increasing amount of PAA. With addition of $\mathrm{MgO}$ to aqueous media in the absence of PAA, a very small amount of $\mathrm{Mg}$ was detected in the supernatant by ICP-AES. Therefore, it was presumed that dissolved Mg species formed a complex, such as magnesium polyacrylate. PAA should play a role as a chelating agent for magnesium ions, i.e., a chelate should be formed between magnesium ions and PAA. The molar ratio of PAA and magnesium ions calculated from the leveled off value in Figs. 2 was 3 at each amount of PAA.

\subsection{Solidification onset time}

Figure 3 shows the effects of the amount of PAA added to the slurries containing 60 mass $\%$ solids loading on the solidification onset time. The onset time increased gradually with increasing amount of PAA until 1.35 mass $\%$ of PAA and then decreased gradually. Taking into account the working time for the shaping process, the optimum amount of PAA was in the range of $1.3-1.5$ mass $\%$ on a dry weight basis relative to the $\mathrm{Al}_{2} \mathrm{O}_{3}-\mathrm{MgO}$ mixed powder for direct casting. 


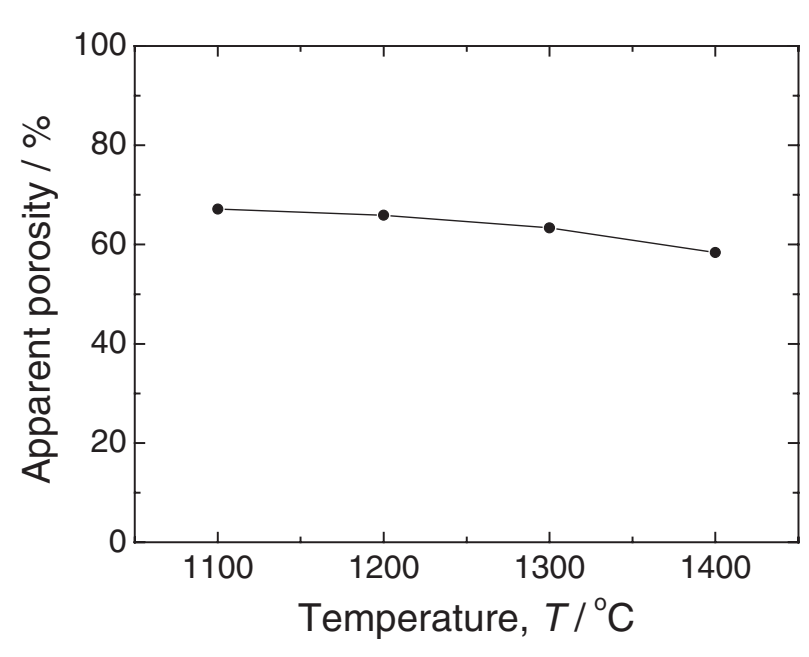

Fig. 4 Effects of firing temperature on the apparent porosity.

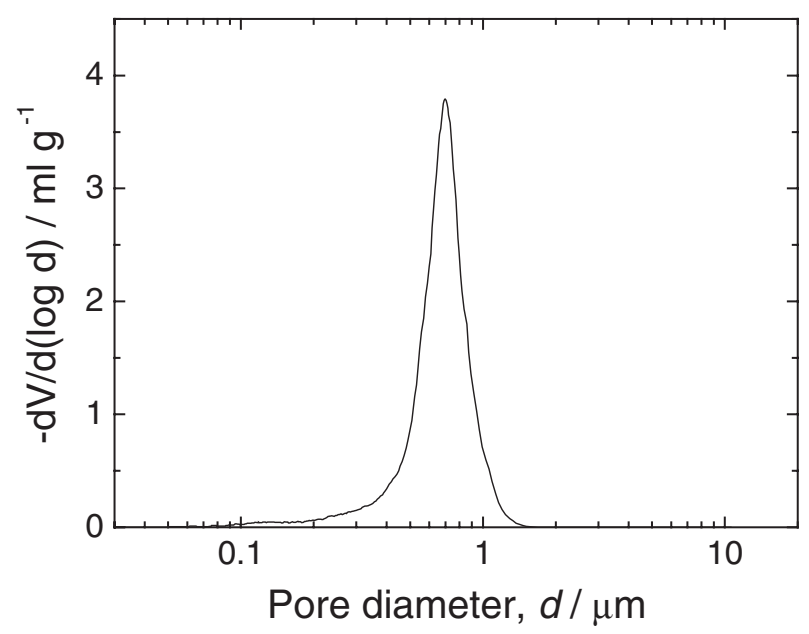

Fig. 5 The pore size distribution curve of the body fired at $1,300^{\circ} \mathrm{C}$ for $2 \mathrm{~h}$.

\subsection{Evaluation of porous bodies}

The green bodies were obtained by drying the solidified bodies fabricated under the conditions described above in climatic chamber with controlled humidity and temperature for $24 \mathrm{~h}$, and then the green bodies were sintered at 1,100 $1,400^{\circ} \mathrm{C}$ for $2 \mathrm{~h}$. Figure 4 shows the apparent porosity of the sintered bodies. The porosity of sintered bodies was about $60 \%$ at each firing temperature. Figure 5 shows the pore size distribution curve of the bodies fired at $1,300^{\circ} \mathrm{C}$ for $2 \mathrm{~h}$. The peak of the curve indicates $0.6 \mu \mathrm{m}$. The trail of the curve on the left hand side indicates the existence of smaller pores. However, the pores were almost monomodal in diameter. Figure 6 shows the X-ray diffraction pattern of the bodies fired at $1,300^{\circ} \mathrm{C}$ for $2 \mathrm{~h}$. The diffraction peaks indicated the existence of $\alpha-\mathrm{Al}_{2} \mathrm{O}_{3}$ and spinel phases. This result showed that $\gamma-\mathrm{Al}_{2} \mathrm{O}_{3}$ as a raw material was converted to $\alpha-\mathrm{Al}_{2} \mathrm{O}_{3}$ and spinel was formed by the reaction of $\mathrm{Al}_{2} \mathrm{O}_{3}$ with $\mathrm{MgO}$ by firing. The porous body was shown to be composed from a composite of $\mathrm{Al}_{2} \mathrm{O}_{3}$ and spinel. Figure 7 shows the threepoint bending strengths of porous composite bodies. The strength increased with increasing firing temperature and a high value of $45 \mathrm{MPa}$ was obtained in the bodies fired at

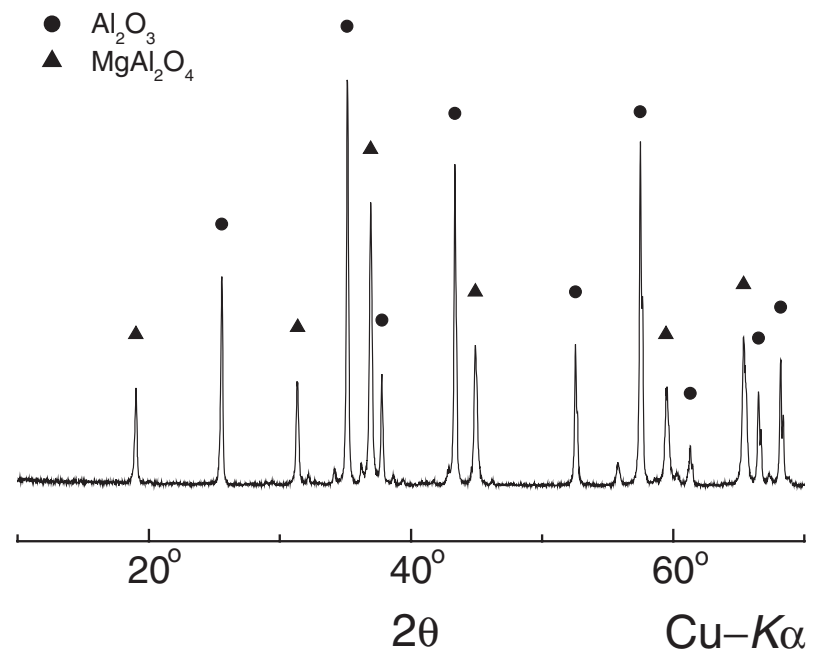

Fig. 6 X-ray diffraction pattern of the body fired at $1,300^{\circ} \mathrm{C}$ for $2 \mathrm{~h}$.



Fig. 7 Three-point bending strengths of porous composite bodies fired at various temperatures.

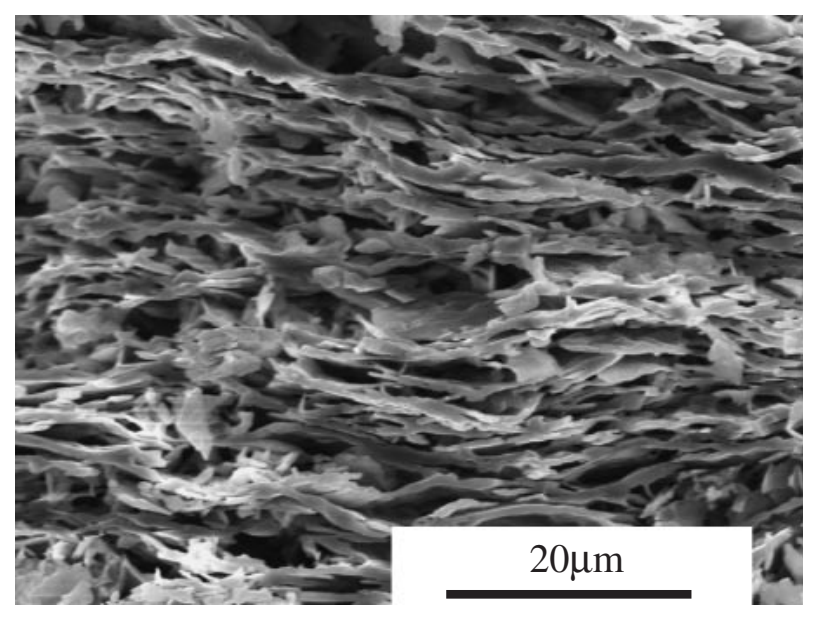

Fig. 8 Scanning electron micrograph of the body fired at $1,300^{\circ} \mathrm{C}$ for $2 \mathrm{~h}$.

$1,300^{\circ} \mathrm{C}$. However, it was not possible to measure the strength in the specimens fired at $1,400^{\circ} \mathrm{C}$ because of their deformation accompanied by shrinkage. Figure 8 shows a scanning electron micrograph of a body fired at $1,300^{\circ} \mathrm{C}$ for 
$2 \mathrm{~h}$. The characteristic structure was observed, i.e., layered and house of cards structures composed of platelet particles were found in the fracture surfaces of the porous body. Pores were observed among the particles. This result indicated the retention of the morphology of original $\mathrm{Al}_{2} \mathrm{O}_{3}$ particles, despite the conversion of $\alpha-\mathrm{Al}_{2} \mathrm{O}_{3}$ from $\gamma-\mathrm{Al}_{2} \mathrm{O}_{3}$ and the formation of spinel by reaction of $\mathrm{Al}_{2} \mathrm{O}_{3}$ with $\mathrm{MgO}$ by firing, as indicated by the results of XRD.

\section{Conclusions}

In the new direct casting method developed in the present study, $\mathrm{MgO}$ added to the $\mathrm{Al}_{2} \mathrm{O}_{3}$ slurry with PAA was effective as a starting reagent to induce solidification of the slurry. The optimum amount of PAA was in the range of 1.31.5 mass $\%$ on a dry weight basis relative to the $\mathrm{Al}_{2} \mathrm{O}_{3}-\mathrm{MgO}$ mixing powder. $\mathrm{MgO}$ was eluted gradually into the aqueous media by the formation of a chelate with PAA. The slurries were solidified by deficiency of PAA because of reduction of the electrostatic repulsive force between the $\mathrm{Al}_{2} \mathrm{O}_{3}$ particles. The degree of shrinkage of the green body on drying was very small, and thus this was regarded as a near-net-shaping process. Porosity of about $60 \%$ and strength of $45 \mathrm{MPa}$ were obtained in the bodies fired at $1,300^{\circ} \mathrm{C}$, and the mean pore diameter was $0.6 \mu \mathrm{m}$.

\section{REFERENCES}

1) W. M. Sigmund, N. S. Bell and L. Bergstrom: J. Am. Ceram. Soc. 83 (2000) 1557-1574.

2) M. A. Janney, O. O. Omatete, C. A Walls, S. D. Nunn, R. J. Ogle and G. Westmoreland: J. Am. Ceram. Soc. 81 (1998) 581-591.

3) I. Santacruz, M. I. Nieto and R. Moreno: J. Am. Ceram. Soc. 85 (2002) 2432-2436.

4) L. J. Gauckler, Th. Graule and F. Baader: Mater. Chem. Phys. 61 (1999) 78-102.

5) B. B. Martin, K. M. Hruschka and L. J. Gauckler: J. Am. Ceram. Soc. 84 (2001) 1733-1739.

6) P. Greil: Mater. Chem. Phys. 61 (1999) 64-68.

7) O. Sakurada, H. Konishi and M. Hashiba: Key Eng. Mater. 206-213 (2002) 381-384.

8) J. A. Lewis: J. Am. Ceram. Soc. 83 (2000) 2341-2359.

9) O. Sakurada, Y. Nakanishi and M. Hashiba: J. Mater. Sci. Lett. 20 (2001) 929-931.

10) H. Okamoto, M. Hashiba, Y. Nurishi and K. Hiramatsu: J. Mater. Sci. 26 (1991) 383-387.

11) M. Hashiba, O. Sakurada, M. Itho, T. Takagi, K. Hiramatsu and Y. Nurishi: J. Mater. Sci. 28 (1993) 4456-4460.

12) M. Hashiba, M. Kawamoto and O. Sakurada: Trans. Mater. Res. Soc. Jpn. 29 (2004) 2041-2044.

13) O. Sakurada, S. Imaeda and M. Hashiba: Trans. Mater. Res. Soc. Jpn. 29 (2004) 2045-2048. 